\title{
Abnormal subcellular distribution of GLUT4 protein in obese and insulin-treated diabetic female dogs
}

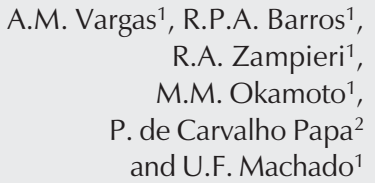

\author{
${ }^{1}$ Departamento de Fisiologia e Biofísica, Instituto de Ciências Biomédicas, \\ Universidade de São Paulo, São Paulo, SP, Brasil \\ ${ }^{2}$ Departamento de Cirurgia, Faculdade de Medicina Veterinária e Zootecnia, \\ Universidade de São Paulo, São Paulo, SP, Brasil
}

Correspondence

U.F. Machado

Departamento de Fisiologia e

Biofísica, ICB, USP

Av. Prof. Lineu Prestes, 1524

05508-900 São Paulo, SP

Brasil

Fax: +55-11-3091-7285

E-mail: ubiratan@fisio.icb.usp.br

Research supported by FAPESP (No. 02/07384-4).

...................

Received July 23, 2003

Accepted April 13, 2004

...................

\begin{abstract}
The GLUT4 transporter plays a key role in insulin-induced glucose uptake, which is impaired in insulin resistance. The objective of the present study was to investigate the tissue content and the subcellular distribution of GLUT4 protein in 4- to 12-year-old control, obese and insulin-treated diabetic mongrel female dogs (4 animals per group). The parametrial white adipose tissue was sampled and processed to obtain both plasma membrane and microsome subcellular fractions for GLUT4 analysis by Western blotting. There was no significant difference in glycemia and insulinemia between control and obese animals. Diabetic dogs showed hyperglycemia $(369.9 \pm 89.9 \mathrm{mg} / \mathrm{dl})$. Compared to control, the plasma membrane GLUT4, reported per $\mathrm{g}$ tissue, was reduced by $55 \%(\mathrm{P}<0.01)$ in obese dogs, and increased by $30 \%(\mathrm{P}<0.05)$ in diabetic dogs, and the microsomal GLUT4 was increased by $\sim 45 \%$ ( $\mathrm{P}<0.001)$ in both obese and diabetic animals. Considering the sum of GLUT4 measured in plasma membrane and microsome as total cellular GLUT4, percent GLUT4 present in plasma membrane was reduced by $\sim 65 \%$ $(\mathrm{P}<0.001)$ in obese compared to control and diabetic animals. Since insulin stimulates GLUT4 translocation to the plasma membrane, percent GLUT4 in plasma membrane was divided by the insulinemia at the time of tissue removal and was found to be reduced by $75 \%(\mathrm{P}<0.01)$ in obese compared to control dogs. We conclude that the insulin-stimulated translocation of GLUT4 to the cell surface is reduced in obese female dogs. This probably contributes to insulin resistance, which plays an important role in glucose homeostasis in dogs.
\end{abstract}

In dogs, type 1 diabetes mellitus (DM1) is more common than type 2 diabetes mellitus (DM2) and generally occurs late in life (1). The prevalence of DM1 in dogs is higher in females than in males, thus suggesting that gonadal function may play a role in DM1
Key words

- Diabetes

- Obesity

- Insulin resistance

- GLUT4

- Adipose tissue

- Plasma membrane

.................. pathophysiology (2). Furthermore, among DM1 dogs, females have a higher frequency of degenerative disease like diabetic cataracts (2).

The number of persons with diabetes mellitus has increased and appears to be 
related to the increased incidence of DM2 as a consequence of modern life style and eating behavior. We may assume that, as is the case for people, insulin resistance and DM2 incidence may also increase in dogs, since the palatability of commercial chows has improved, at the same time that physical activity has decreased, inducing obesity. In dogs, obesity occurs late in life and is more frequent in females than in males, with a higher prevalence in neutered animals (3).

Obesity, DM2 and insulin-treated DM1 are clearly related to insulin resistance (4), and information about the mechanisms involved has contributed to the development of new therapeutic approaches. GLUT4 protein is a glucose transporter mainly expressed in white adipose tissue and skeletal muscle, and related to insulin-induced glucose uptake since the hormone is able to promote a rapid translocation of the transporter from an intracellular pool to the plasma membrane (5). GLUT4 content and/or translocation have been reported to be reduced in diabetes mellitus and obesity both in humans (6) and in several experimental models of diabetic or obese rodents (7), clearly playing a key role in insulin resistance. Since the GLUT4 protein has not been investigated in obese and diabetic dogs, the present study was carried out in order to determine the amount and subcellular distribution of this transporter in obese and insulin-treated diabetic female dogs.

Female dogs were selected at the Veterinary Hospital of the Faculty of Veterinary Medicine, University of São Paulo (HOVETUSP Hospital), from animals which had been submitted to ovariosalpingectomy. Animals were 4- to 12-year-old mongrel female dogs, and their body condition was analyzed according to the body condition scoring proposed by Laflamme (8) to determine ideal or obese body condition. Additionally, animals from all groups had plasma progesterone levels lower than $0.75 \mathrm{ng} / \mathrm{dl}$. Control animals had an ideal body condition, absence of data suggesting the presence of diabetes mellitus, and fasting plasma glucose lower than 110 $\mathrm{mg} / \mathrm{dl}$. Obese animals had the same profile as controls, except for their obese body condition. Animals with diagnosed DM1 had an ideal body condition and were under insulin treatment (1 to $2 \mathrm{U} /$ day NPH insulin; IOLIN, Biobras, Montes Claros, MG, Brazil).

Based on these criteria, 4 animals were investigated in each group. The experimental protocol (protocol \#85/99) was approved by the Ethics Committee for Animal Research (CEEA) of the Institute of Biomedical Sciences, University of São Paulo.

The surgical procedures were carried out according to the protocol of the HOVETUSP hospital. Surgeries were performed between 9:00 am and 3:00 pm after 12-h food and 2-h water deprivation. During a presurgical period of $30 \mathrm{~min}$, the body condition of the animals was determined, and $5 \mathrm{ml}$ of blood was taken from the radial vein for analysis. The diabetic animals did not receive their daily morning insulin dose and, according to their blood glucose concentration, they were started on a regular insulin schedule during surgery after tissue sampling. The anesthetic procedure included pre-anesthetic drugs $(50 \mu \mathrm{g} / \mathrm{kg}$ acepromazine and $2 \mathrm{mg} / \mathrm{kg}$ meperidine), anesthetic induction drugs ( 0.5 $\mathrm{mg} / \mathrm{kg}$ midazolam and $5 \mathrm{mg} / \mathrm{kg}$ ketamine), and anesthetic maintenance (halothane inhalation). As soon as the abdominal cavity was assessed, the parametrial white adipose tissue was sampled, weighed and immediately snap-frozen in liquid nitrogen for GLUT4 protein analysis (see below).

Subcellular white adipose tissue was fractionated as described (9). Briefly, tissue samples were homogenized in 1:7/weight: volume buffer $(10 \mathrm{mM}$ Tris $\mathrm{HCl}, 1 \mathrm{mM}$ EDTA, $250 \mathrm{mM}$ sucrose, $5 \mu \mathrm{g} / \mathrm{ml}$ leupeptin, and $15 \mu \mathrm{g} / \mathrm{ml}$ aprotinin, $\mathrm{pH}$ 7.4). After centrifugation at $3,000 \mathrm{~g}$ for $15 \mathrm{~min}$, the fatfree extract was centrifuged at $12,000 \mathrm{~g}$ for $20 \mathrm{~min}$, and the pellet thus obtained was suspended in $0.5 \mathrm{ml}$ buffer, resulting in a plasma membrane-rich fraction. The super- 
natant was then centrifuged at 20,000 $g$ for $20 \mathrm{~min}$, and the resulting supernatant was centrifuged at $150,000 \mathrm{~g}$ for $60 \mathrm{~min}$. The final pellet was suspended in $0.5 \mathrm{ml}$ buffer, thus providing the microsomal fraction (M). Protein concentration of the samples was determined by the method of Bradford. Equal amounts of membrane protein $(150 \mu \mathrm{g})$ from samples were separated by SDS-PAGE and then electrotransferred onto a nitrocellulose membrane. After electrotransfer the membranes were first incubated with the antiGLUT4 antibody (1:200), and then with [125I]-labeled protein-A (Amersham Pharmacia Biotech, Amersham, UK). After a final washing step, the membranes were exposed to autoradiography for 20 days at $-70^{\circ} \mathrm{C}$. The signals obtained were quantified by densitometry (Image Master 1D ${ }^{\circledR}$, Pharmacia Biotech, Uppsala, Sweden), and the results are reported as arbitrary units (AU) per $\mu \mathrm{g}$ protein. Four experiments were performed, each with a different set of control, obese and diabetic samples.

Blood was collected immediately before the beginning of the anesthetic procedure. Plasma samples were assayed for glucose by the glucose oxidation method with a kit obtained from Analisa Diagnostica (Belo Horizonte, MG, Brazil), and insulin and progesterone levels were measured with the "Coat-a-Count" radioimmunoassay (RIA) from Diagnostic Products Corporation (Los Angeles, CA, USA); the assays were conducted according to the instructions provided by the suppliers. All samples were analyzed for insulin or progesterone in the same RIA assay, and the intra-assay coefficients of variation were $<8.7$ and $<9.3 \%$, respectively, for insulin and progesterone (one low and one high standard control sample for insulin or progesterone were assayed in 10 pairs of tubes in each assay). Based on the fasting glucose $(\mathrm{mg} / \mathrm{dl})$ and insulin $(\mu \mathrm{U} /$ $\mathrm{ml}$ ) concentrations of control and obese animals, the glucose/insulin (G/I) index was calculated as a measure of in vivo insulin sensitivity.

Taking into account the total protein recovery in each membrane fraction and the tissue weight, the GLUT4 content per g tissue was obtained (9). Using the GLUT4/g tissue value of the plasma membrane (PM) and microsome $(\mathrm{M})$ fractions of each animal, the subcellular distribution (SD) of GLUT4 was calculated as follows: $\mathrm{SD}=(\mathrm{PM}$ $\mathrm{x} 100) /(\mathrm{PM}+\mathrm{M})$. This value is reported as $\%$ and represents the relative amount of GLUT4 that was present in the plasma membrane at the time of tissue removal. All data are reported as means \pm SEM for 4 animals and were analyzed by ANOVA followed by the Student-Newman-Keuls as a post-test.

Metabolic and hormonal profile of the animals. Four animals in each group were studied, with no difference in mean age (control, $6.75 \pm 1.88$ years; obese, $5.75 \pm$ 0.63 years; diabetic, $6.75 \pm 1.03$ years). The metabolic and hormonal profile of the animals is shown in Table 1. There was no difference in glycemia between control and obese animals, whereas diabetic animals were clearly hyperglycemic $(\mathrm{P}<0.01 v s$ control and obese animals). Although there was no statistical difference, the mean insulinemia of obese animals was two-fold higher than control animals, whereas the mean value of the $\mathrm{G} / \mathrm{I}$ index was $25 \%$ lower than the control value. Finally, although the mean plasma progesterone level was higher $(\mathrm{P}<0.01)$ in diabetic animals, the highest individual value

Table 1. Metabolic and hormonal parameters of control, obese and insulin-treated diabetic female dogs.

\begin{tabular}{lcccc}
\hline Animals & $\begin{array}{c}\text { Glycemia } \\
(\mathrm{mg} / \mathrm{dl})\end{array}$ & $\begin{array}{c}\text { Insulinemia } \\
(\mu \mathrm{U} / \mathrm{ml})\end{array}$ & $\begin{array}{c}\mathrm{G} / \mathrm{l} \\
\text { index }\end{array}$ & $\begin{array}{c}\text { Progesteronemia } \\
(\mathrm{ng} / \mathrm{dl})\end{array}$ \\
\hline Control & $90.5 \pm 6.7$ & $4.13 \pm 0.57$ & $22.8 \pm 2.38$ & $0.18 \pm 0.03$ \\
Obese & $95.5 \pm 6.6$ & $8.75 \pm 3.33$ & $16.9 \pm 6.63$ & $0.14 \pm 0.003$ \\
Diabetic & $369.9 \pm 89.9 *$ & - & - & $0.42 \pm 0.06^{*}$
\end{tabular}

Data are reported as mean \pm SEM for 4 animals. Insulinemia and glucose/insulin $(G / l)$ index were not determined in insulin-treated diabetic animals.

${ }^{*} \mathrm{P}<0.01$ vs control and obese animals (ANOVA followed by the Student-NewmanKeuls post hoc test). 


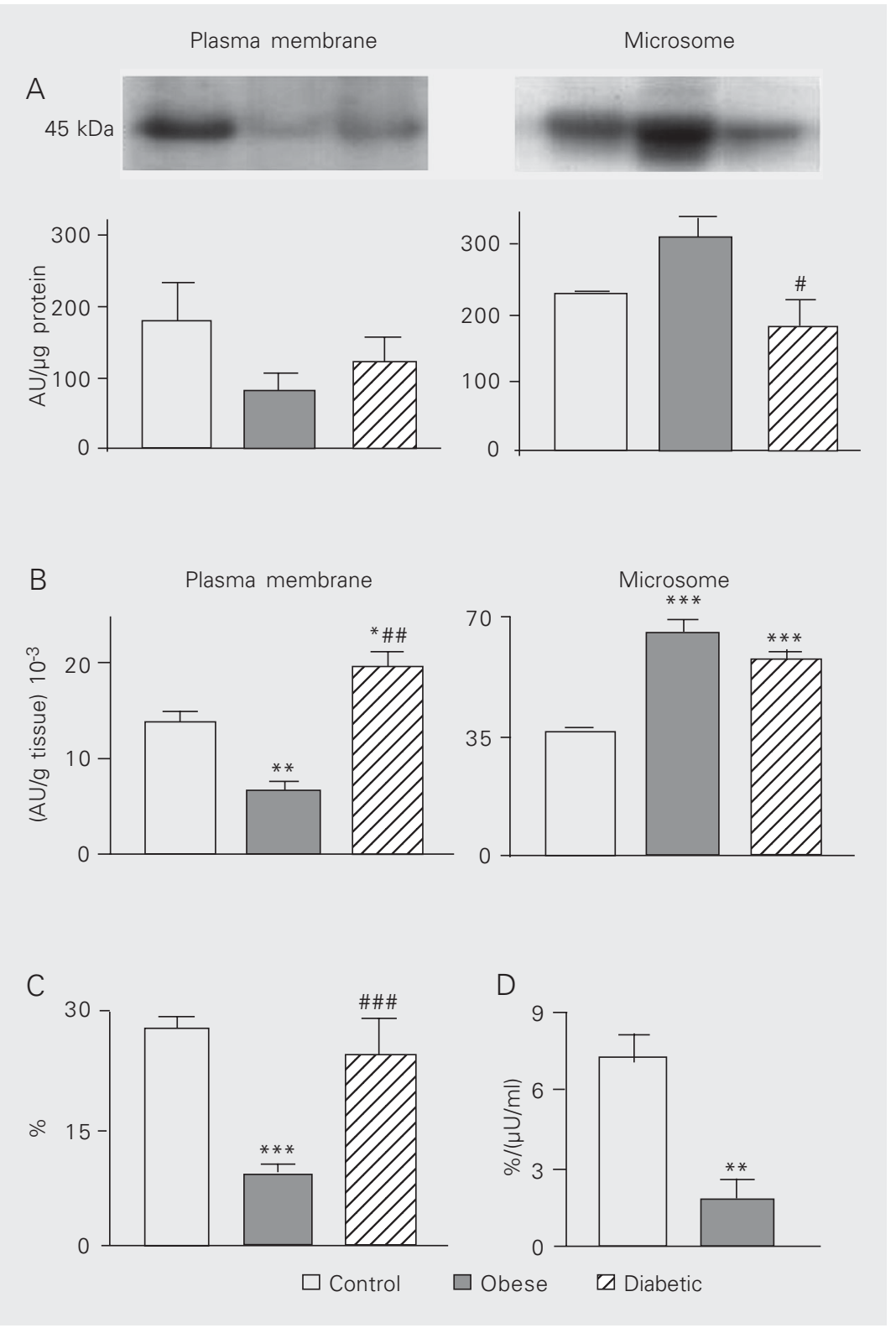

Figure 1. GLUT4 protein in control, obese and insulin-treated diabetic female dogs. The GLUT4 protein was assessed in the plasma membrane (PM) and microsome (M) subcellular fractions of white adipose tissue of control (open columns), obese (filled columns) and insulin-treated diabetic (hatched columns) female dogs. Equal amounts of total protein were immunoblotted to GLUT4. A, Top, representative autoradiograms of GLUT4 with the molecular weight of the blots; Bottom, results reported as arbitrary units (AU) per $\mu \mathrm{g}$ of total protein electrophoresed. In $B$, the results for the PM and $M$ fractions are reported as AU per $g$ tissue. In $C$, the sum of PM and M GLUT4 per $g$ tissue was considered to be the total cellular GLUT4 content $(100 \%)$. The percent of the total GLUT4 present in PM at the time of tissue removal is shown in C. D, The percent cellular GLUT4 in the PM of control and obese animals was divided by their insulinemia $(\mu \mathrm{U} / \mathrm{ml})$ at the time of tissue removal. Results are reported as the mean \pm SEM for 4 animals analyzed in 4 different experiments. ${ }^{*} P<0.05$, ${ }^{*} P<0.01$, ${ }^{*}{ }^{*} P<0.001$ vs control value; ${ }^{\#} P<0.05$, $\#$ \# $<0.01$, \#\#\# $<0.001$ vs obese value (ANOVA followed by the Student-Newman-Keuls post hoc test). was $0.56 \mathrm{ng} / \mathrm{ml}$, confirming that no bitch was in the estrous phase.

GLUT4 protein content in white adipose tissue. The GLUT4 content, reported as AU per $\mu \mathrm{g}$ protein loaded for electrophoresis, is shown in Figure 1A. Although the mean plasma membrane GLUT4 content did not differ significantly among groups, the obese group showed a 50\% reduction in this value compared to the control group. In contrast, the microsome GLUT4 content was significantly reduced $(\mathrm{P}<0.05)$ in the diabetic group compared to the obese group. The GLUT4 content, expressed as AU per $g$ tissue, was calculated on the basis of the tissue protein content in each subcellular membrane fraction, and the results are shown in Figure 1B. The plasma membrane content of GLUT4/g tissue was reduced $(\mathrm{P}<0.01)$ in obese animals compared to both control and diabetic animals; furthermore, the value for the diabetic group was higher $(\mathrm{P}<0.05)$ than that for the control group. Concerning the microsome GLUT4/g tissue, a similar increase $(\mathrm{P}<0.001)$ was observed in obese and diabetic animals compared to control animals.

Plasma membrane GLUT4 as a percentage of total recovered GLUT4. Considering the sum of plasma membrane and microsome GLUT4 content, reported per $\mathrm{g}$ tissue, as the total cellular GLUT4 content (100\%), the percentage of this value detected in the plasma membrane fraction is the amount of GLUT4 recovered in the plasma membrane at the time of tissue removal. Figure $1 \mathrm{C}$ shows that the percentage of GLUT4 in the plasma membrane was similar in control and diabetic animals, and greatly reduced in obese animals $(\mathrm{P}<0.001 v s$ control and diabetic animals). Since this distribution is a consequence of insulin activity, the percentage of GLUT4 obtained for control and obese animals was divided by their respective plasma insulin concentrations. The response to insulin was strongly reduced in obese animals ( $\mathrm{P}$ $<0.01$ vs control; Figure 1C). This analysis 
was not performed in diabetic animals under insulin therapy since their plasma insulin concentration probably does not reflect the true amount of biologically active hormone.

The increasing incidence of obesity and diabetes mellitus in Western populations emphasizes the importance of determining the mechanisms involved in their pathophysiology (10). As also reported in the literature (2), the prevalence of diabetes mellitus in dogs treated at the HOVET-USP hospital is higher among females, and most of these animals are mixed-breed dogs, as in the present study. It is clear that some breeds show a different incidence of diabetes, and mixed-breed dogs have been used as the reference point to determine whether certain breeds are at low or high risk to develop diabetes mellitus (11).

In the present study, the ovariosalpingectomy surgeries were elective and decided by the owner of the control and obese dogs. However, in diabetic female dogs, ovariosalpingectomy is usually clinically indicated to improve metabolic control (12). During estrus, most diabetic female dogs lose metabolic control, even with an increase in their daily insulin dose, suggesting a role of gonadal function in metabolic homeostasis and/ or insulin effectiveness (12). Additionally, changes in glycosylated hemoglobin concentrations throughout the ovarian cycle have been reported in diabetic female dogs (13). The influence of the ovarian cycle on metabolic control has been proposed to occur in healthy human females whose insulin sensitivity is reduced in the luteal phase (14). The luteal and estrous phases of humans and dogs, respectively, are characterized, among other features, by high plasma progesterone levels, which may be involved in the reduction of insulin sensitivity $(13,14)$. For this reason, in the present study we selected subjects out of estrus, and although the diabetic dogs showed higher mean plasma progesterone levels, these levels differed considerably from those occurring during estrus. The influence of gonadal function on glucose homeostasis is an important feature which is not clearly understood. Treatment of female dogs with synthetic progestins has been shown to impair glucose homeostasis, determining hyperinsulinemia and insulin resistance, and some of these animals develop diabetes mellitus $(15,16)$.

The metabolic parameters observed in obese dogs were not sufficient to clearly show an insulin-resistant condition. However, compared to control dogs, the mean plasma insulin levels were twice higher and the $\mathrm{G} / \mathrm{I}$ value was $25 \%$ lower in obese dogs, suggesting the occurrence of in vivo insulin resistance as defined in humans (17) and in rodents (9).

In contrast, the plasma glucose levels of the diabetic female dogs under study were very high despite the insulin treatment. It is important to point out that blood was collected immediately before induction of anesthesia. Stress-induced hyperglycemia has been reported to occur in dogs, involving increased glucose production in both liver and kidney (18). Furthermore, the hyperglycemic response to experimental stress has been reported to be 6-fold greater in diabetic than in normal dogs (18), and hyperinsulinemia does not prevent this effect of stress, unless accompanied by beta-blockade (19).

Although skeletal muscle is the main tissue involved in insulin-induced glucose clearance, white adipose tissue metabolism has been considered an important modulator of glucose homeostasis. By balancing glucose utilization and lipolysis (10), as the white adipose tissue becomes insulin resistant the plasma free-fatty-acids increase and the glucose utilization by muscle is inhibited, impairing glucose homeostasis (10). Thus, the white adipose tissue GLUT4 protein plays a key role in glucose homeostasis (10).

We report here for the first time the modulation of GLUT4 protein content in white adipose tissue from obese and insulintreated diabetic dogs. In the present study, 
the GLUT4 protein content reported per $g$ of tissue, which has an important functional meaning in the true ability of the tissue to take up glucose (9), was significantly altered in obese animals. Reduced plasma membrane GLUT4 content/g tissue was observed in obese female dogs, suggesting a reduced basal glucose uptake. However, increased microsome GLUT4 content/g tissue was also observed, reflecting an increase of total cellular GLUT4 content. Increased GLUT4 content has been reported in earlier stages of obesity, which may be followed by reduced GLUT4 translocation and GLUT4 expression, as obesity and insulin resistance develop (20). Taken as a whole, the results obtained here for obese female dogs suggest that, as observed in other species such as rat $(7,9)$, mice (7) and human (6), obesity induces a tissue insulin-resistant condition, which may lead to impaired glucose homeostasis later on.

It is important to note that the present diabetic dogs were under insulin treatment, and thus the results should be considered to be a consequence of impaired glucose homeostasis and/or of insulin treatment, but never as a feature of the insulin-deprived condition. Compared to controls, diabetic bitches showed increased GLUT4 content in both plasma membrane and microsomes when expressed per $g$ of tissue, which may be a consequence of increased number of small adipocytes characteristic of the catabolic conditions. The percent of total GLUT4 recovered in the plasma membrane was similar to that observed in controls and higher than that observed in obese dogs. This behavior of GLUT4 in diabetic dogs might have been induced by hyperglycemia and/or insulin treatment.

Thus, the microsomal fraction GLUT4 protein content is increased in white adipose tissue from obese dogs, whereas in the same tissue from insulin-treated diabetic dogs the transporter content is increased in both plasma membrane and microsome fractions. In view of the plasma insulin concentration of obese dogs, the results suggest a reduction in GLUT4 translocation from the intracellular sites to the plasma membrane, reflecting a tissue insulin-resistant condition.

\section{Acknowledgments}

The authors would like to thank Dr. Adauri Brezolin for a careful English revision.

\section{References}

1. Fleeman LM \& Rand JS (2001). Management of canine diabetes. Veterinary Clinics of North America. Small Animal Practice, 31: 855880.

2. Salgado D, Reusch C \& Spiess B (2000). Diabetic cataracts: different incidence between dogs and cats. Schweizer Archiv für Tierheilkunde, 142: 349-353.

3. Edney AT \& Smith PM (1986). Study of obesity in dogs visiting veterinary practices in the United Kingdom. Veterinary Record, 118: 391-396.

4. De Fronzo RA \& Ferranini E (1991). Insulin resistance, a multifaceted syndrome responsible for NIDDM, obesity, hypertension, dislipidemia, and atherosclerotic cardiovascular disease. Diabetes Care, 14: 173-194.

5. Slot JW, Geuze HJ, Gigengack S, Lienhard GE \& James DE (1991). Immuno-localization of the insulin regulatable glucose transporter in brown adipose tissue of the rat. Journal of Cell Biology, 113: 123-135.
6. Garvey WT, Maianu L, Huecksteadt TP, Birnbaum MJ, Molina JM \& Ciaraldi TP (1991). Pretranslational suppression of a glucose transporter protein causes insulin resistance in adipocytes from patients with non-insulin-dependent diabetes mellitus and obesity. Journal of Clinical Investigation, 87: 1072-1081.

7. Klip A, Tsakiridis T, Marette A \& Ortiz PA (1994). Regulation of expression of glucose transporters by glucose: a review of studies in vivo and in cell cultures. FASEB Journal, 8: 43-53.

8. Laflamme DP (1994). Estimation of body fat by body condition score. Journal of Veterinary Internal Medicine, 8: 154 (Abstract).

9. Seraphim PM, Nunes MT \& Machado UF (2001). GLUT4 protein expression in obese and lean 12-month-old rats: insights from different types of data analysis. Brazilian Journal of Medical and Biological Research, 34: 1353-1362.

10. Bergman RN, Van Citters GW, Mittelman SD, Dea MK, HamiltonWessler M, Kim SP \& Ellmerer M (2001). Central role of the adipocyte in the metabolic syndrome. Journal of Investigative 
Medicine, 49: 119-126.

11. Hess RS, Kass PH \& Ward CR (2000). Breed distribution of dogs with diabetes mellitus admitted to a tertiary care facility. Journal of the American Veterinary Medical Association, 216: 1414-1417.

12. Staudacher $G$ (1985). Fructosamine determination as a tool in the prognosis of diabetes mellitus in dogs. Berliner und Münchener Tieraerztliche Wochenschrift, 108: 418-420.

13. Escalante Pulido JM \& Alpizar Salazar M (1999). Changes in insulin sensitivity, secretion and glucose effectiveness during menstrual cycle. Archives of Medical Research, 30: 19-22.

14. Marca MC \& Loste A (2000). Glycosylated haemoglobin assay of canine blood samples. Journal of Small Animal Practice, 41: 189192.

15. Selman PJ, Mol JA, Rutteman GR \& Rijnberk A (1994). Progestin treatment in the dog. 1. Effects on growth hormone, insulin-like growth factor 1 and glucose homeostasis. European Journal of Endocrinology, 131: 413-421.

16. McCann JP, Altszuler N, Hampshire J \& Concannon PW (1987)
Growth hormone, insulin, glucose, cortisol, luteinizing hormone, and diabetes in beagle bitches treated with medroxyprogesterone lactate. Acta Endocrinologica, 116: 73-80.

17. Caro JF (1991). Insulin resistance in obese and nonobese man Journal of Clinical Endocrinology and Metabolism, 73: 691-696.

18. Miles PD, Yamatani K, Lickley HL \& Vranic M (1991). Mechanism of glucoregulatory responses to stress and their deficiency in diabetes. Proceedings of the National Academy of Sciences, USA, 88: 1296-1300.

19. Rashid S, Shi ZQ, Niwa M, Mathoo JM, Vandelangeryt ML, Bilinski D, Lewis GF \& Vranic M (2000). Beta-blockade, but not normoglycemia or hyperinsulinemia, markedly diminishes stress-induced hyperglycemia in diabetic dogs. Diabetes, 49: 253-262.

20. de Carvalho Papa P, Vargas AM, da Silva JL, Nunes MT \& Machado UF (2002). GLUT4 protein is differently modulated during development of obesity in monosodium glutamate-treated mice. Life Sciences, 71: 1917-1928. 